\title{
Desempenho em Pastagens e Características de Carcaça da 16무 Progênie dos Rebanhos Nelore, Guzerá e Caracu de Sertãozinho (SP) ${ }^{1}$
}

\section{Alexander George Razook 2,4, Leopoldo Andrade de Figueiredo², Ana Cláudia Ruggieri², Romeu Fernandes Nardon ${ }^{3}$, Joslaine Noely dos Santos Gonçalves Cyrillo $2,4,5$}

\begin{abstract}
RESUMO - Quarenta e um machos inteiros dos rebanhos selecionados para peso aos 378 dias (P378), nascidos em 1996, foram terminados em pastagens de Panicum Maximum (Jacq.), Panicum Maximum (Jaq) cv. Tanzania 1 e Brachiaria brizantha (Hoschst) Stapf cv. Marandu na Estação Experimental de Zootecnia de Sertãozinho (SP). As amostras, representando a média de P378 em cada rebanho, foram: 11 animais Nelore Seleção $(\mathrm{NeS})$ e 10 para cada um dos grupos Nelore Controle (NeC), Guzerá Seleção (GuS) e Caracu (Ca). O abate ocorreu aos 824 dias de idade e condição corporal 7,6, em uma escala de 1 a 9. As médias mínimas e máximas ajustadas, para as principais características, considerando-se todos os grupos, foram: ganho de peso médio diário, $406(\mathrm{NeC})$ e $501 \mathrm{~g}(\mathrm{NeS})$; peso de abate (PAB), 446,8 (NeC) e 544,3 kg (NeS) ; peso de carcaça (PCAR), 249,8 (NeC) e 309,7 kg (NeS); rendimento de carcaça (REND), 54,0

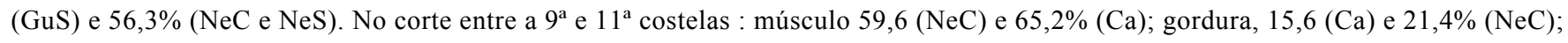
osso, 18,9 ( NeC) e 20,2\% (GuS); espessura de gordura (ESPGOR), 2,0 (Ca) e 4,2 mm (NeC); área de olho de lombo (AOL), 65,6 (NeC) e 71,1 $\mathrm{cm}^{2}(\mathrm{NeS}$ e $\mathrm{Ca}$ ); força de cisalhamento (FC), 4,5 (Ca) e 6,6 kg (GuS) e perdas totais no cozimento (PERDAS), 22,5 (NeC) e 24,9\% (GuS). A seleção para peso provocou, em NeS, maiores PAB e PCAR, sem interferir no REND, na composição da costela, FC e PERDAS na carne. Houve, porém, menor ESPGOR em relação à NeC. Os animais GuS apresentaram PAB e PCAR intermediários, entre NeS e $\mathrm{Ca}$, e menor REND e os Ca maior proporção de músculo na costela e carne com maior maciez em relação ao Zebu.
\end{abstract}

Palavras-chave: composição corporal, força de cisalhamento, ganho de peso, maciez de carne, rendimento de carcaça, seleção

\section{Performance on Pasture and Carcass Traits of the $16^{\text {th }}$ Selected Progenies of Sertãozinho (SP-Brazil) Nelore, Guzera and Caracu Herds}

\begin{abstract}
Forty one young bulls of herds selected for 378 day's weight (W378), born in 1996, were finished on pastures of Panicum Maximum (Jacq.), Panicum Maximum (Jaq) cv. Tanzania 1 and Brachiaria brizantha (Hoschst) Stapf cv. Marandu at the Sertãozinho Experimental Station, São Paulo State, Brazil. The samples, representing the W378 mean for each herd, were composed by 11 Nellore Selection ( $\mathrm{NeS}$ ) and by 10 of each one of the groups Nelore Control (NeC), Guzera Selection (GuS) and Caracu (Ca). The slaughter was carried out when the animals were 824 days older, with a body condition score averaging 7.6, in a 1-9 scale. The minimum and maximum adjusted means for the main traits, including all groups, were: average weight daily gain, 406 ( $\mathrm{NeC}$ ) and $501 \mathrm{~g}(\mathrm{NeS})$; slaughter weight (SW), $446.8(\mathrm{NeC})$ and $544.3 \mathrm{~kg}(\mathrm{NeS})$; carcass weight (CW), $249.8(\mathrm{NeC})$ and $309.7 \mathrm{~kg}(\mathrm{NeS})$; dressing percentage (DP), $54.0(\mathrm{GuS})$ and $56.3 \%(\mathrm{NeC}$ and $\mathrm{NeS})$. In the $9^{\text {th }}-11^{\text {th }}$ rib section: muscle, $59.6(\mathrm{NeC})$ and $65.2 \%(\mathrm{Ca})$; fat, $15.6(\mathrm{Ca})$ and $21.4 \%(\mathrm{NeC})$; bone, $18.9(\mathrm{NeC})$ and 20.2\% (GuS); fat thickness (FT), $2.0(\mathrm{Ca})$ and $4.2 \mathrm{~mm}(\mathrm{NeC})$; loin eye area, $65.6(\mathrm{NeC})$ and $71.1 \mathrm{~cm}^{2}(\mathrm{NeS}$ and Ca); Warner-Bratzler shear force (SF), $4.5(\mathrm{Ca})$ and $6.6 \mathrm{~kg}(\mathrm{GuS})$ and total cooking losses (TCL), $22.5(\mathrm{NeC})$ and 24.9\% (GuS). The selection for weight promoted higher SW and CW in the NeS group, without changing the DP, the physical composition of the rib, SF and TCL in the meat. However, there was lower FT compared to NeC. The GuS animals had intermediates SW and CW, compared to NeS and Ca and lower DP. The Ca animals presented higher muscle percentage, in the rib section, and also higher meat tenderness compared to the meat of the Zebu animals.
\end{abstract}

Key Words: body composition, daily gain, dressing percentage, meat tenderness, shear force

\section{Introdução}

Os rebanhos Zebu (Nelore, Guzerá e Gir) e Caracu da Estação Experimental de Zootecnia de Sertãozinho são selecionados desde o final da década de 70 para um único critério em cada sexo. Esse critério tem sido o peso pós-desmame, que, nos machos, é obtido ao final das Provas de Ganho de Peso (PGP), em confinamento, e padronizado a 378 dias (P378); nas fêmeas, o peso é padronizado a 550

\footnotetext{
${ }^{1}$ Parte do Projeto IZ-14-011/80.

2 Pesquisador Científico - IZ - EEZ de Sertãozinho-C.P. 63 - CEP 14160-900 - Sertãozinho - SP. E.mail: razook@izsp.br, figueiredo@izsp.br, ruggieri@izsp.br, cyrillo@izsp.br

3 Pesquisador Científico - Instituto de Zootecni. E.mail: nardon@izsp.br

${ }^{4}$ Bolsista do CNPq.

5 Pós-Graduação - Produção Animal - UNESP - Jaboticabal.
} 
dias (P550), sob regime de pasto. A avaliação da mudança genética nesses caracteres e, nos correlacionados, como pesos ao nascer, ao desmame, ganhos diários de peso e características morfológicas, tem sido feita com o auxílio de uma população da raça Nelore não selecionada, ou controle, cujos reprodutores são escolhidos com diferenciais nulos nos mesmos critérios de seleção. Várias publicações da literatura mostraram o progresso genético alcançado nas características de crescimento de seleção direta e correlacionadas, destacando-se Packer et al. (1986), Razook et al. (1988a,b), Razook et al. (1993), Razook et al. (1998) e Cyrillo et al. (2000).

Após duas gerações de seleção, ou seja, nas progênies nascidas após 10 anos de seleção, tornouse importante verificar os efeitos desse processo em características de abate e de qualidade de carcaça. Isso foi realizado a partir das progênies nascidas em 1992, com os estudos de Nardon (1998) e Nardon et al. (1998 a,b,c), que analisaram características de carcaça das progênies nascidas daquele ano a 1994, terminadas em confinamento e em três pontos de abate. Razook et al. (2001) mostraram resultados da seleção na $15^{\text {a }}$ progênie dos rebanhos Zebu e Caracu, também terminadas em confinamento até atingir um ponto único de abate, avaliado por condição corporal. Já Resende et al. (2000; 2001) mostraram resultados de carcaça referentes à $17^{\mathrm{a}}$ progênie do projeto de Sertãozinho e, desta vez, com terminação em confinamento com dois níveis de concentrado na dieta e, finalmente, Vittori et al. (2001) apresentaram resultados referentes à $18^{\mathrm{a}}$ progênie mantida também em confinamento, porém, com metade da amostra tendo sido castrada com um ano de idade. Todos esses trabalhos, portanto, avaliaram amostras dos rebanhos de Sertãozinho em regime de confinamento, mostrando que a seleção para peso determinou principalmente maiores pesos de carcaça, sem, contudo, provocar alterações na qualidade da carcaça e da carne.

Este estudo foi conduzido com o objetivo de mostrar resultados em características de desempenho, de abate e de carcaça de amostras da $16^{\mathrm{a}}$ progênie dos rebanhos Nelore, Guzera e Caracu da Estação Experimental de Zootecnia de Sertãozinho, terminadas em regime de pastagem.

\section{Material e Métodos}

Os dados analisados neste trabalho foram provenientes de animais produzidos nos rebanhos Guzerá Seleção e Tradicional (GuS), Nelore Seleção e Tradicional (NeS) e Caracu (Ca) da Estação Experimental de Zootecnia de Sertãozinho, sendo progênies de touros com altos diferenciais de seleção para P378 e de fêmeas para P550, e no rebanho Nelore Controle $(\mathrm{NeC})$, com reprodutores de diferenciais em torno de zero nos mesmos critérios de seleção. Todos os animais representaram grupos contemporâneos nascidos no $2^{\circ}$ semestre (Setembro a Novembro) de 1996 e participaram da Prova de Ganho de Peso (PGP) de 1997 de acordo com a metodologia descrita por Razook et al. (1997). Esses animais foram da $16^{\mathrm{a}}$ progênie produzida dentro de cada rebanho, representando 3,7 gerações (valor médio do coeficiente de geração) de seleção a partir dos reprodutores fundadores. Ao final da PGP, amostras constituídas de animais inteiros foram separadas obedecendo-se à média de P378 de cada rebanho, em um total de 10 animais para cada rebanho e 11 no NeS. A Tabela 1 apresenta as médias das amostras, bem como das populações originais avaliadas na PGP de 1997, verificando-se que houve boa representatividade do material original.

Após o término da PGP em 7/10/1997, os animais foram mantidos nos mesmos recintos da PGP até 22/ $12 / 1997$, quando foram encaminhados para terminação a pasto. De acordo com as informações de Ruggieri et al. (1999), a partir de 07/01/1998, os animais receberam uma suplementação mineral energética e aditivada comercial na base de um $\mathrm{kg}$ / dia, permanecendo em vários tipos de pastagem como Brachiaria brizantha (Hoschst) Stapf cv. Marandu, capim Tanzânia (Panicum maximum (Jacq) cv Tanzânia-1) e capim colonião (Panicum maximum (Jacq). A suplementação mineral de um $\mathrm{kg}$ perdurou até 18/09/1998. Após essa data, a suplementação aumentou para um e meio $\mathrm{kg}$ até 6/11/1998, quando então acrescentou-se ao suplemento um $\mathrm{kg}$ de milho moído, para acelerar a terminação, até o abate.

O abate dos animais ocorreu no dia 16/01/1999, no Frigorífico Angelelli, em Piracicaba (SP), com idade média de 824 dias. $\mathrm{O}$ peso de abate (PAB) foi 
Tabela 1 - Número de observações na população original $(\mathrm{N})$, amostra $(\mathrm{n})$, médias dos pesos aos 378 dias de idade para a população original (média 1) e amostra (média 2) e relação entre elas, por rebanho

Table 1 - Number of observations in the original population ( $N)$, sample (n), means for W378 weight for the original population and sample and means ratio (sample/original population), by herd

\begin{tabular}{|c|c|c|c|c|c|}
\hline \multirow[b]{2}{*}{$\begin{array}{l}\text { Rebanho } \\
\text { Herd }\end{array}$} & \multicolumn{2}{|c|}{$\begin{array}{l}\text { População original } \\
\text { Original population }\end{array}$} & \multicolumn{2}{|c|}{$\begin{array}{l}\text { Amostra } \\
\text { Sample }\end{array}$} & \multirow{2}{*}{$\begin{array}{c}\text { Relação } \\
\text { Ratio } \\
\text { Média 2/Média } 1 \\
\text { Mean 2/Mean 1 }\end{array}$} \\
\hline & $\begin{array}{c}\text { Média } 1 \\
\text { Mean } 1\end{array}$ & $\mathrm{~N}$ & $\begin{array}{l}\text { Média } 2 \\
\text { Mean } 2 \\
\end{array}$ & $\mathrm{n}$ & \\
\hline $\begin{array}{l}\text { Guzerá seleção } \\
\text { Guzerá selection }\end{array}$ & 321,6 & 73 & 323,0 & 10 & $1,00(+0,4 \%)$ \\
\hline $\begin{array}{l}\text { Nelore controle } \\
\text { Nellore control }\end{array}$ & 268,1 & 25 & 267,4 & 10 & $1,00(-0,3 \%)$ \\
\hline $\begin{array}{l}\text { Nelore seleção } \\
\text { Nellore selection }\end{array}$ & 313,2 & 85 & 318,4 & 11 & $1,02(+1,7 \%)$ \\
\hline $\begin{array}{l}\text { Caracu } \\
\text { Caracu } \\
\text { Total }\end{array}$ & 351,9 & 57 & 347,3 & 10 & $0,99(-1,3 \%)$ \\
\hline
\end{tabular}

obtido um dia anterior, em jejum, com a atribuição de uma nota de condição corporal, por exame visual, obedecendo-se à escala de 1 a 9 , de acordo com o procedimento descrito pelo Beef Improvement Federation-BIF (1996). No abate, realizado de acordo com os procedimentos normais de um frigorífico sob inspeção federal, obteve-se os pesos de carcaça quente (PCAR), do fígado (FIG), da gordura renal e pélvica (GREN), separados na linha de esfola e evisceração. Após o resfriamento das carcaças por 48 horas, separou-se da meia-carcaça esquerda uma seção transversal compreendendo a $9^{\mathrm{a}}, 10^{\mathrm{a}}$ e $11^{\mathrm{a}}$ costelas, conforme procedimento de Hankins e Howe (1946). Esses cortes foram transportados ao laboratório de carnes do Instituto de Zootecnia, em Nova Odessa (SP), onde foram pesados e seus componentes físicos separados em músculo (MUSC), gordura (GORD) e osso (OSSO). Cada componente foi também pesado para a obtenção da composição do corte, em termos percentuais em relação à peça inteira. Ainda no corte, foram obtidas a área do músculo Longissimus dorsi (contrafilé), denominada área de olho de lombo (AOL) e a espessura de gordura de cobertura (ESPGOR) no mesmo. Posteriormente, para análise qualitativa da carne, uma amostra do contrafilé foi preparada conforme o manual de cozimento e avaliação sensorial da carne descrito por Cross et al. (1978). Nessa amostra foram avaliadas a força de cisalhamento (FC), que fornece indicação do grau de maciez da carne, em amostras cozidas do músculo longissimus dorsi submetidas ao teste com o aparelho "Warner Bratzler", e as perdas totais (PERDAS) por evaporação e drenagem, durante o cozimento.

As análises de variância, as estimativas das médias por quadrados mínimos e os contrastes, comparando-se o Nelore Controle $(\mathrm{NeC})$ versus demais grupos genéticos e o Caracu $(\mathrm{Ca})$ versus Zebu, foram efetuadas pelo programa LSMLMW (Harvey, 1990). Aplicou-se também o teste Tukey, de comparação múltipla entre médias observadas, por meio do programa SAS, Statistical Analysis System (SAS, 1985). Foram analisadas as características: ganho diário em pastagem (GDP); de abate: pesos de abate (PAB), de abate padronizado a 824 dias (PA824), de carcaça quente (PCAR), rendimento de carcaça (REND), arrobas de carcaça (ARROB), condição corporal no abate (CC), pesos e percentuais em relação a $\mathrm{PAB}$ do fígado (FIG e PFIG) e gordura renal e pélvica

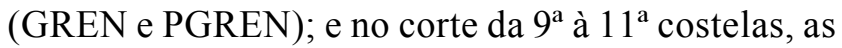
porcentagens de músculo (MUSC), gordura (GORD) e osso (OSSO). Ainda desse corte foram analisadas as características consideradas como de qualidade de carcaça: espessura de gordura (ESPGOR), tomada como uma média de três pontos, e área de olho de lombo (AOL) e de qualidade de carne: força de cisalhamento (FC) e porcentagem de perdas totais por cozimento (PERDAS). Os modelos estatísticos, na análise de variância, incluiram os efeitos de rebanho (grupos genéticos) e da regressão linear de idade ao abate (ou idade inicial no GDP). 


\section{Resultados e Discussão}

Na Tabela 2 são apresentados os valores mínimos, máximos e médios, acompanhados dos respectivos desvios-padrão e coeficientes de variação (CV), de todas as características referentes aos 41 animais que compuseram a amostra deste estudo. Durante um período a pasto de 465 dias, os animais ganharam, em média, $453 \mathrm{~g} / \mathrm{dia}$, refletindo ganhos de peso bas- tante variáveis no período, conforme relataram Ruggieri et al. (1999).

Mesmo assim, o grupo atingiu aos 824 dias de idade (cerca de 27 meses) um peso de abate (P824) médio de $508 \mathrm{~kg}$, com condição corporal (CC) média de 7,6 (em escala de 1 a 9), o que pode ser considerado como abaixo do ideal, em termos de acabamento. Esse aspecto também foi verificado pela espessura de gordura (ESPGOR) no contrafilé, que ficou com

Tabela 2 - Valores mínimos, máximos e médios, desvios-padrão (DP) e coeficientes de variação (CV) para características de desempenho, abate e carcaça

Table 2 - Minimum, maximum and mean values, standard deviations (SD) and variation coefficient (VC) for performance, slaughter and carcass traits

\begin{tabular}{|c|c|c|c|c|c|}
\hline $\begin{array}{l}\text { Variável } \\
\text { Variable }\end{array}$ & $\begin{array}{l}\text { Mínimo } \\
\text { Minimum }\end{array}$ & $\begin{array}{l}\text { Máximo } \\
\text { Maximum }\end{array}$ & $\begin{array}{l}\text { Média } \\
\text { Mean }\end{array}$ & $\begin{array}{l}\text { DP } \\
S D\end{array}$ & $\mathrm{CV}$ \\
\hline Idade de abate (dias) & 763 & 877 & 824 & 28,3 & 3,4 \\
\hline $\begin{array}{l}\text { Slaughter age (days) } \\
\text { Condição corporal }{ }^{1}\end{array}$ & 6,5 & 8,0 & 7,6 & 0,4 & 5,2 \\
\hline $\begin{array}{l}\text { Slaughter condition score } \\
\text { Ganho médio diário }{ }^{2}(\mathrm{~g}) \\
\text { Daily weight gain }^{2}\end{array}$ & 342,0 & 576,0 & 453,5 & 54,2 & 12,0 \\
\hline $\begin{array}{l}\text { Peso abate }(\mathrm{kg}) \\
\text { Slaughter weight }(\mathrm{SW})\end{array}$ & 407,0 & 596,0 & 507,7 & 50,2 & 9,9 \\
\hline $\begin{array}{l}\text { Peso abate } 824 \text { dias }(\mathrm{kg}) \\
\text { Slaughter weight at } 824 \text { days }\end{array}$ & 434,0 & 585,0 & 508,0 & 46,3 & 9,1 \\
\hline $\begin{array}{l}\text { Peso carcaça }(\mathrm{kg}) \\
\text { Carcass weight }\end{array}$ & 218,5 & 337,5 & 281,8 & 29,9 & 10,6 \\
\hline $\begin{array}{l}\text { Rendimento }(\%) \\
\text { Dressing percentage }\end{array}$ & 51,6 & 58,6 & 55,5 & 1,6 & 2,9 \\
\hline $\begin{array}{l}\text { Arrobas (@) }{ }^{3} \\
\text { Peso fígado }(\mathrm{kg})\end{array}$ & $\begin{array}{l}14,6 \\
4,4\end{array}$ & $\begin{array}{l}22,5 \\
7,6\end{array}$ & $\begin{array}{l}18,8 \\
5,6\end{array}$ & $\begin{array}{l}2,0 \\
0,8\end{array}$ & $\begin{array}{l}10,6 \\
13,6\end{array}$ \\
\hline Liver weight & & & & & \\
\hline $\begin{array}{l}\text { Fígado (\% peso abate) } \\
\text { Liver (\% of SW) }\end{array}$ & 1,0 & 1,3 & 1,1 & 0,1 & 8,6 \\
\hline $\begin{array}{l}\text { Peso gordura renal }(\mathrm{kg}) \\
\text { Kidnev fat }(\mathrm{kg})\end{array}$ & 1,3 & 4,6 & 2,8 & 0,8 & 27,9 \\
\hline $\begin{array}{l}\text { Gord. ren. (\% peso abate) } \\
\text { Kidney fat (\% of SW }\end{array}$ & 0,3 & 1,0 & 0,6 & 0,2 & 29,0 \\
\hline $\begin{array}{l}\text { Músculo (\% no corte })^{4} \\
\text { Muscle } \geq\end{array}$ & 53,8 & 68,9 & 62,2 & 3,7 & 5,9 \\
\hline $\begin{array}{l}\text { Gordura (\% no corte) } \\
\text { Fat }\end{array}$ & 12,7 & 26,3 & 18,2 & 3,6 & 20,0 \\
\hline $\begin{array}{l}\text { Osso (\% no corte) } \\
\text { Bone }\end{array}$ & 16,5 & 23,8 & 19,5 & 1,7 & 8,5 \\
\hline $\begin{array}{l}\text { Espessura gordura (mm) } \\
\text { Fat thickness }\end{array}$ & 0,0 & 6,0 & 2,8 & 1,5 & 53,6 \\
\hline $\begin{array}{l}\text { Área olho lombo }\left(\mathrm{cm}^{2}\right) \\
\text { Longissimus dorsi area }\end{array}$ & 56,1 & 80,6 & 68,9 & 6,3 & 9,1 \\
\hline $\begin{array}{l}\text { Força cisalhamento }(\mathrm{kg}) \\
\text { Shear force }\end{array}$ & 3,0 & 9,2 & 5,7 & 1,2 & 21,9 \\
\hline $\begin{array}{l}\text { Perdas cozimento }(\%) \\
\text { Total cooking losses }\end{array}$ & 17,5 & 30,1 & 23,7 & 3,0 & 12,8 \\
\hline
\end{tabular}

${ }^{1}$ Escala de 1 a 9 (no abate) (1 - 9 scale [at slaughter]).

2 Ganho diário a pasto (daily gain on pasture).

${ }^{3}$ Cada arroba $=15 \mathrm{~kg}$ (each @ = $15 \mathrm{~kg}$ ).

${ }^{4}$ Corte entre a $9^{\mathrm{a}}$ e $11^{\mathrm{a}}$ costela (Muscle, fat and bone percentages in the $9-11^{\text {th }}$ rib section).

R. Bras. Zootec., v.31, n.3, p.1367-1377, 2002 (suplemento) 
um valor médio de $2,8 \mathrm{~mm}$ e extremamente variável $(\mathrm{CV}=53,6 \%)$. O rendimento de carcaça (REND) médio foi de $55,5 \%$ ou 18,8 arrobas, com um peso médio de carcaça (PCAR) de $281,8 \mathrm{~kg}$, considerando-se todos os grupos genéticos. As menores variações ocorreram no rendimento de carcaça e idade de abate, e as maiores para as características indicativas de grau de acabamento (ESPGOR e GREN). Outra característica com grande variação foi a força de cisalhamento, apresentando um valor médio de $5,7 \mathrm{~kg}$, o que é considerado alto para padrões de maciez de carne.

A Tabela 3 apresenta as médias ajustadas, por quadrados mínimos, para o ganho de peso diário em pastagens e as características obtidas no abate dos animais, por rebanho ou grupo genético. A Tabela 4 mostra as médias ajustadas para as características de qualidade de carcaça e da carne, também por grupo genético. Em ambas as tabelas, existem as comparações entre médias pelo teste de Tukey, bem como o nível de significância da ANOVA para a fonte de

Tabela 3 - Médias ajustadas por quadrados mínimos ${ }^{1}$ ( \pm erros-padrão) para características de desempenho e abate por rebanho

Table 3 - Least square means ${ }^{1}$ ( \pm standard errors) for performance and slaughter traits by herd

\begin{tabular}{|c|c|c|c|c|c|}
\hline $\begin{array}{l}\text { Caráter } \\
\text { Trait }\end{array}$ & $\begin{array}{l}\text { Guzerá seleção } \\
\text { Guzerá selection }\end{array}$ & $\begin{array}{l}\text { Nelore controle } \\
\text { Nellore control }\end{array}$ & $\begin{array}{l}\text { Nelore seleção } \\
\text { Nellore selection }\end{array}$ & $\begin{array}{l}\text { Caracu } \\
\text { Caracu }\end{array}$ & $\mathrm{NS}^{2}$ \\
\hline Idade final prova ${ }^{3}$ (dias) & 347 & 351 & 374 & 361 & \\
\hline $\begin{array}{l}\text { Final age in performance test (days) } \\
\text { Peso final prova }{ }^{3}(\mathrm{~kg})\end{array}$ & 283,8 & 251,0 & 324,7 & 324,9 & \\
\hline $\begin{array}{l}\text { Final weight in performance test } \\
\text { Idade de abate } 4 \text { (dias) } \\
\text { Slaughter age } \text { (days) }^{4}\end{array}$ & 812 & 816 & 841 & 826 & \\
\hline $\begin{array}{l}\text { Condiç̧ão corporal } \\
\text { Condition score }\end{array}$ & $7,7 \pm 0,1^{\mathrm{ab}}$ & $7,4 \pm 0,1^{\mathrm{ab}}$ & $7,9 \pm 0,1^{\mathrm{a}}$ & $7,4 \pm 0,1^{b}$ & $0,02(*)$ \\
\hline $\begin{array}{l}\text { Ganho médio diário }(\mathrm{g}) \\
\text { Weight daily gain }\end{array}$ & $443,4 \pm 14,0^{\mathrm{ab}}$ & $406,4 \pm 13,9^{\mathrm{b}}$ & $501,2 \pm 13,8^{\mathrm{a}}$ & $458,2 \pm 13,7^{\mathrm{ab}}$ & $0,02(*)$ \\
\hline $\begin{array}{l}\text { Peso de abate }(\mathrm{kg}) \\
\text { Slaughter weight }\end{array}$ & $499,5 \pm 8,7^{b}$ & $446,8 \pm 8,6^{\mathrm{c}}$ & $544,3 \pm 8,5^{\mathrm{a}}$ & $536,4 \pm 8,5^{\mathrm{a}}$ & $0,00(* *)$ \\
\hline $\begin{array}{l}\text { Peso de abate } 824 \text { dias }(\mathrm{kg}) \\
\text { Slaughter weight at } 824 \text { days }\end{array}$ & $500,9 \pm 8,6^{\mathrm{b}}$ & $447,6 \pm 8,6^{\mathrm{c}}$ & $542,7 \pm 8,2^{\mathrm{a}}$ & $537,3 \pm 8,6^{\mathrm{a}}$ & $0,00(* *)$ \\
\hline $\begin{array}{l}\text { Peso de carcaça }(\mathrm{kg}) \\
\text { Carcass weight }\end{array}$ & $267,2 \pm 5,8^{b}$ & $249,8 \pm 5,8^{b}$ & $309,7 \pm 5,5^{\mathrm{a}}$ & $297,7 \pm 5,8^{\mathrm{a}}$ & $0,00(* *)$ \\
\hline $\begin{array}{l}\text { Arrobas no abate }(@)^{5} \\
\text { @ at slaughter }\end{array}$ & $17,8 \pm 0,4^{b}$ & $16,7 \pm 0,4^{b}$ & $20,6 \pm 0,4^{\mathrm{a}}$ & $19,8 \pm 0,4^{\mathrm{a}}$ & $0,00(* *)$ \\
\hline $\begin{array}{l}\text { Rendimento }(\%) \\
\text { Dressing percentage }\end{array}$ & $54,0 \pm 0,4^{b}$ & $56,3 \pm 0,4^{\mathrm{a}}$ & $56,3 \pm 0,4^{\mathrm{a}}$ & $55,4 \pm 0,4^{\mathrm{a}}$ & $0,00(* *)$ \\
\hline $\begin{array}{l}\text { Peso do fígado }(\mathrm{kg}) \\
\text { Liver weight }\end{array}$ & $5,3 \pm 0,1^{b c}$ & $4,8 \pm 0,1^{\mathrm{c}}$ & $5,7 \pm 0,1^{b}$ & $6,5 \pm 0,1^{\mathrm{a}}$ & $0,00(* *)$ \\
\hline $\begin{array}{l}\text { Fígado ( } \% \text { peso abate }) \\
\text { Liver weight }\end{array}$ & $1,1 \pm 0,0^{\mathrm{b}}$ & $1,1 \pm 0,0^{\mathrm{b}}$ & $1,0 \pm 0,0^{\mathrm{b}}$ & $1,2 \pm 0,0^{\mathrm{a}}$ & $0,00(* *)$ \\
\hline $\begin{array}{l}\text { Peso gordura renal }(\mathrm{kg}) \\
\text { Kidney fat weight }\end{array}$ & $2,2 \pm 0,2^{b}$ & $3,0 \pm 0,2^{\mathrm{ab}}$ & $3,2 \pm 0,2^{\mathrm{a}}$ & $2,8 \pm 0,2^{\mathrm{ab}}$ & $0,03(* *)$ \\
\hline $\begin{array}{l}\text { Gord. ren. (\% peso abate) } \\
\text { Kidney fat (\% of SW) }\end{array}$ & $0,4 \pm 0,0^{\mathrm{b}}$ & $0,7 \pm 0,0^{\mathrm{a}}$ & $0,6 \pm 0,0^{\mathrm{ab}}$ & $0,5 \pm 0,0^{\mathrm{ab}}$ & $0,01(*)$ \\
\hline $\begin{array}{l}\text { Músculo (\% na } 9^{\mathrm{a}}-11^{\mathrm{a}} \text { costela) } \\
\text { Muscle (\% in the } 9^{\text {th }}-11^{\text {th }} \text { rib section) }\end{array}$ & $63,1 \pm 1,0^{\mathrm{ab}}$ & $59,6 \pm 1,0^{b}$ & $61,2 \pm 0,9^{b}$ & $65,2 \pm 1,0^{\mathrm{a}}$ & $0,00(* *)$ \\
\hline $\begin{array}{l}\text { Gordura ( } \% \text { na } 9^{\mathrm{a}}-11^{\mathrm{a}} \text { costela) } \\
\text { Fat (\% in the } 9^{\text {th }}-11^{\text {th }} \text { rib section) }\end{array}$ & $16,7 \pm 0,9^{\mathrm{bc}}$ & $21,4 \pm 0,9^{\mathrm{a}}$ & $19,1 \pm 0,9^{a b}$ & $15,6 \pm 0,9^{\mathrm{c}}$ & $0,00(* *)$ \\
\hline $\begin{array}{l}\text { Osso }\left(\% \text { na } 9^{a}-11^{a} \text { costela }\right) \\
\text { Bone (\% in the } 9^{\text {th }}-11^{\text {th }} \text { rib section) }\end{array}$ & $20,2 \pm 0,5^{\mathrm{a}}$ & $18,9 \pm 0,5^{\mathrm{a}}$ & $19,7 \pm 0,5^{\mathrm{a}}$ & $19,3 \pm 0,5^{\mathrm{a}}$ & 0,39 (ns) \\
\hline
\end{tabular}

${ }^{1}$ Valores na linha, acompanhados de mesma letra não diferem entre si pelo teste de Tukey $(P>0,05)$.

2 NS: Nível de significância da ANOVA para efeito de rebanho. ns: não significativo; $\left({ }^{*}\right)$ significativo $(P<0,05) ;\left({ }^{* *}\right)$ significativo $(P<0,01)$.

3 Peso e Idade Final na Prova de Ganho de Peso e início do período de terminação (médias observadas).

${ }^{4}$ Médias observadas.

${ }^{1}$ Means in the same line, followed by the same letter, do not differ $(P>0.05)$ by Tukey test.

2 LS: Level of significance from the ANOVA for herd effect. ns: non significant; $\left({ }^{*}\right)$ significant $(P<0.05) ;\left({ }^{* *}\right)$ significant $(P<0.01)$.

${ }^{3}$ Final weight and age in the performance test.

${ }^{4}$ Observed means; ${ }^{5}$ each @=15 kg. 
Tabela 4 - Médias ajustadas ${ }^{1}$ por quadrados mínimos, ( \pm erros-padrão) por característica de qualidade de carcaça e carne, por rebanho

Table 4 - Least square means ${ }^{1}$ ( \pm standard errors) for carcass and meat quality traits by herd

\begin{tabular}{|c|c|c|c|c|c|}
\hline $\begin{array}{l}\text { Caráter } \\
\text { Trait }\end{array}$ & $\begin{array}{l}\text { Guzerá seleção } \\
\text { Guzera selection }\end{array}$ & $\begin{array}{l}\text { Nelore controle } \\
\text { Nellore control }\end{array}$ & $\begin{array}{l}\text { Nelore seleção } \\
\text { Nellore selection }\end{array}$ & $\begin{array}{l}\text { Caracu } \\
\text { Caracu }\end{array}$ & $\mathrm{NS}^{2}$ \\
\hline Espessura de gordura $(\mathrm{mm})$ & $2,3 \pm 0,4^{\mathrm{b}}$ & $4,2 \pm 0,4^{\mathrm{a}}$ & $2,9 \pm 0,4^{\mathrm{ab}}$ & $2,0 \pm 0,4^{\mathrm{b}}$ & $0,00(* *)$ \\
\hline $\begin{array}{l}\text { Fat thickness } \\
\text { Área olho lombo }\left(\mathrm{cm}^{2}\right) \\
\text { Loin eye area }\end{array}$ & $66,4 \pm 1,8^{\mathrm{a}}$ & $65,6 \pm 1,8^{\mathrm{a}}$ & $71,7 \pm 1,7^{\mathrm{a}}$ & $71,7 \pm 1,8^{\mathrm{a}}$ & $0,03(*)$ \\
\hline $\begin{array}{l}\text { Força cisalhamento }(\mathrm{kg}) \\
\text { Shear force }\end{array}$ & $6,6 \pm 0,3^{\mathrm{a}}$ & $5,9 \pm 0,3^{\mathrm{a}}$ & $5,7 \pm 0,3^{\mathrm{ab}}$ & $4,5 \pm 0,3^{\mathrm{b}}$ & $0,00(* *)$ \\
\hline Perdas cozimento (\%) & $24,9 \pm 1,0^{\mathrm{a}}$ & $22,5 \pm 1,0^{\mathrm{a}}$ & $23,8 \pm 0,9^{\mathrm{a}}$ & $23,9 \pm 1,0^{\mathrm{a}}$ & $0,37(\mathrm{~ns})$ \\
\hline
\end{tabular}

Total cooking losses

${ }^{1}$ Valores na linha, acompanhados de mesma letra, não diferem entre si pelo teste de Tukey $(P>0,05)$

2 NS: Nível de significância da ANOVA para efeito de rebanho. ns: não significativo; $\left({ }^{*}\right)$ significativo $(P<0,05) ;\left({ }^{* *}\right)$ significativo $(P<0,01)$.

${ }^{1}$ Means in the same line, followed by the same letter, do not differ $(P>0.05)$ by Tukey test.

${ }^{2}$ LS: Level of significance from the ANOVA for herd effect. ns: not significant; $\left({ }^{*}\right)$ significant $(P<0.05)$; $\left({ }^{* *}\right)$ significant $(P<0.01)$

variação de rebanhos. A Tabela 5 apresenta o nível de significância dos contrastes, obtidos por funções lineares, comparando a população controle em relação aos demais grupos, e animais Caracu em relação aos Zebu. A Tabela 6 apresenta uma comparação, em valores percentuais, das principais características deste estudo de cada rebanho em relação ao rebanho controle.

O ganho diário em pastagem (GDP), foi menor para $\mathrm{NeC}(406 \mathrm{~g} /$ dia $)$ e inferior $(\mathrm{P}<0,05)$ ao $\mathrm{NeS}$, que apresentou um valor máximo de $501 \mathrm{~g} / \mathrm{dia}$. Os grupos Gus e Ca apresentaram ganhos de peso intermediários e não diferentes estatisticamente do NeS. Pelos contrastes (Tabela 5), verifica-se que $\mathrm{NeC}$ foi inferior $(\mathrm{P}<0,01)$ aos demais grupos genéticos, o que não ocorreu na comparação de Caracu com os animais Zebu.

Com relação aos pesos de abate (Tabela 3), tanto PAB como PA824, com valores muito próximos, as menores médias foram para $\mathrm{NeC}(447 \mathrm{~kg})$ e as maiores para $\mathrm{NeS}(543 \mathrm{~kg}$ ), que não diferiram significativamente do Caracu $(537 \mathrm{~kg})$. Os animais do rebanho GuS foram intermediários entre $\mathrm{NeC}$ e os demais rebanhos. Pela comparação por contrastes (Tabela 5), os animais $\mathrm{NeC}$ diferiram significativamente dos demais grupos, o mesmo ocorrendo com $\mathrm{Ca}$ em relação a todos grupos Zebu. O peso de abate é uma característica correlacionada com o critério de seleção nos rebanhos, que é P378. No Nelore seleção, o ganho genético estimado é em torno de $1,1 \%$ da média de P378 ao ano e em GuS um pouco inferior (0,8\% ao ano), de acordo com Razook et al. (1998).
Pela Tabela 6 verifica-se que as amostras denotam, nessa $16^{\mathrm{a}}$ progênie, um ganho acumulado em P378 (em torno de 20\%) em relação ao $\mathrm{NeC}$. No caso do Guzerá, a média de P378 desse grupo contemporâneo excedeu um pouco o esperado para essa progênie, considerando-se a taxa de ganho genético em todo o rebanho. A comparação percentual reflete, nos grupos Nelore, respostas correlacionadas devido exclusivamente à seleção para peso, e na comparação de $\mathrm{NeC}$ com os demais grupos (GuS e Ca), efeitos raciais e também de respostas correlacionadas. No peso de abate (P824) houve no Nelore a manutenção da superioridade alcançada em P378 (+ 21\% em relação a $\mathrm{NeC})$, o que não ocorreu com GuS $(+12 \%)$. Essa redução de superioridade deveu-se principalmente aos menores ganhos em pastagem, em relação ao NeS. Esses menores ganhos reduziram a vantagem, em relação a $\mathrm{NeC}$ de P378 para P824 (de um ano de idade até o abate), tanto nos animais GuS (de 20 para 12\%), como em Ca (de 30 para $20 \%$ ).

Com relação ao peso de carcaça (PCAR) os maiores valores foram alcançados no $\mathrm{NeS}(310 \mathrm{~kg})$ e $\mathrm{Ca}(298 \mathrm{~kg})$, que não diferiram $(\mathrm{P}>0,05)$ entre si. Animais GuS apresentaram carcaças com peso intermediário (267 kg), porém, não diferentes estatisticamente de $\mathrm{NeC}$ que foi de $250 \mathrm{~kg}$ (Tabela 3). Em valores percentuais verifica-se que as vantagens em relação a NeC no P824 mantiveram-se em PCAR no $\mathrm{NeS}$ e $\mathrm{Ca}$, porém, isso não ocorreu no grupo $\mathrm{GuS}$ $(+7 \%)$, conforme apresentado na Tabela 6. Essa menor vantagem foi provocada principalmente pelo 
menor rendimento de carcaça nos animais do rebanho Guzerá (54\%), tendo sido significativamente menor em relação aos demais grupos. Animais Nelore apresentaram rendimento quente de $56 \%$ e Caracu 55\% (Tabela 3). Observando-se os contrastes (Tabela 5) o rendimento de $\mathrm{NeC}$ foi superior aos demais grupos em conjunto e o rendimento do Ca não diferiu de animais Zebu. Ainda na Tabela 3, constam as médias ajustadas para os pesos do fígado, da gordura perirrenal e pélvica, também transformados em percentagens do PAB. O peso do fígado de animais Caracu, expresso como porcentagem do $\mathrm{PAB}$, foi significativamente mais pesado que dos animais dos outros grupos (Tabela 5), por outro lado, animais $\mathrm{NeC}$ mostraram ter fígados mais leves (Tabela 3), porém, em termos percentuais, em relação ao peso de abate, isso não ocorreu. Em valores percentuais em relação ao $\mathrm{PAB}$, animais Caracu também apresentaram fígados mais pesados. Com relação à gordura renal, indicativa de grau de acabamento, não houve diferença significativa na comparação de $\mathrm{NeC}$ com demais grupos em termos quantitativos (Tabela 3 ), porém, em valores percentuais em relação à $\mathrm{PAB}, \mathrm{o} \mathrm{NeC}$ apresentou as maiores médias, diferindo significativamente do grupo GuS. Comparando-se somente os animais Nelore, não houve diferenças significativas entre esses grupos, como consequência indireta da seleção para peso no acúmulo de gordura perirrenal. Em valores percentuais em relação à $\mathrm{NeC}$ (Tabela 6), verifica-se que tanto em termos quantitativos, como percentuais, os grupos $\mathrm{GuS}$ e Ca foram inferiores na quantidade de gordura renal.

Com relação à composição física do corte entre a $9^{\mathrm{a}}$ e $11^{\mathrm{a}}$ costelas, verificou-se que a porcentagem de músculo (MUSC) não diferiu entre $\mathrm{NeC}$ e NeS. Os animais $\mathrm{Ca}$ apresentaram a maior porcentagem de músculo, diferindo de animais Nelore. Na comparação por contrastes (Tabela 5), verificou-se que MUSC dos animais $\mathrm{NeC}$ foi menor que nos demais grupos, contrariamente à Ca que possui a maior musculosidade, comparado aos Zebu. Na percentagem de gordura (GORD), também não houve diferenças significativas entre $\mathrm{NeS}$ e $\mathrm{NeC}$, os quais mostraram ter maior proporção de gordura no corte do que animais $\mathrm{Ca}$ com valor semelhante ao GuS. A porcentagem de osso no corte (OSSO) também não apresentou diferenças devidas à seleção $(\mathrm{NeS}$ vs $\mathrm{NeC})$ nem entre os vários grupos genéticos.

A comparação dos resultados encontrados neste estudo, nas características de abate, com outros da literatura é uma difícil tarefa, principalmente tratando-se de animais inteiros, terminados em pastagem e pertencentes a grupos genéticos bastante específicos, submetidos à uma seleção direcional para peso pós-desmame. Em geral, as características de abate, carcaça e qualidade da carne são extremamente dependentes de idade ao abate, manejo e alimentação de engorda, procedimentos no abate, castração, outros efeitos ambientais, e da constituição genética. Além desses aspectos citados, a terminação em pastagem é, geralmente, mais lenta, devido não só à

Tabela 5 - Nível de significância $\left(\mathrm{NS}^{1}\right)$ dos contrastes que comparam Nelore Controle com demais rebanhos e Caracu em relação ao Zebu, por caráter

Table 5 - Level of significance $\left(L S^{1}\right)$ of the contrasts comparing Nellore control versus other groups and Caracu versus Zebu, by trait

\begin{tabular}{|c|c|c|}
\hline $\begin{array}{l}\text { Caráter } \\
\text { Trait }\end{array}$ & $\begin{array}{l}\mathrm{NeC} \text { vs outros (NS) } \\
\mathrm{NeC} \text { vs others }\end{array}$ & $\begin{array}{c}\text { Ca vs Zebu (NS) } \\
C a \text { vs Zebu LS }\end{array}$ \\
\hline $\begin{array}{l}\text { Ganho médio diário } \\
\text { Weight daily gain }\end{array}$ & $0,00(* *)$ & $0,62(\mathrm{~ns})$ \\
\hline $\begin{array}{l}\text { Peso de abate } \\
\text { Slaughter weight }\end{array}$ & $0,00(* *)$ & $0,00(* *)$ \\
\hline Peso de abate 824 dias & $\quad 0,00(* *)$ & $0,00(* *)$ \\
\hline $\begin{array}{l}\text { Slaughter weight at } 824 \\
\text { Condição corporal } \\
\text { Condition score }\end{array}$ & $\begin{array}{l}4 \text { days } \\
\qquad 0,15(\mathrm{~ns})\end{array}$ & $0,05(*)$ \\
\hline $\begin{array}{l}\text { Peso de carcaça } \\
\text { Carcass weight }\end{array}$ & $0,00(* *)$ & $0,00(* *)$ \\
\hline $\begin{array}{l}\text { Rendimento } \\
\text { Dressing percentage }\end{array}$ & $0,03(*)$ & $0,82(\mathrm{~ns})$ \\
\hline $\begin{array}{l}\text { Peso do fígado } \\
\text { Liver weight }\end{array}$ & $0,00(* *)$ & $0,00(* *)$ \\
\hline $\begin{array}{l}\text { Fígado }(\% \mathrm{PAB}) \\
\text { Liver }(\% \mathrm{SW})\end{array}$ & $0,39(\mathrm{~ns})$ & $0,00(* *)$ \\
\hline $\begin{array}{l}\text { Peso gordura renal } \\
\text { Kidney fat }\end{array}$ & $0,34(\mathrm{~ns})$ & 0,95 (ns) \\
\hline $\begin{array}{l}\text { Gord. ren.(\% } \% \text { PAB }) \\
\text { Kidney fat }(\% \text { SW) }\end{array}$ & $0,01(*)$ & $0,49(\mathrm{~ns})$ \\
\hline $\begin{array}{l}\text { Músculo (\% no corte) } \\
\text { Muscle (cut \%) }\end{array}$ & $0,00(* *)$ & $0,00(* *)$ \\
\hline $\begin{array}{l}\text { Gordura ( } \% \text { no corte }) \\
\text { Fat }(\text { cut } \%)\end{array}$ & $0,00(* *)$ & $0,00(* *)$ \\
\hline $\begin{array}{l}\text { Osso ( } \% \text { no corte }) \\
\text { Bone }(\text { cut } \%)\end{array}$ & $0,22(\mathrm{~ns})$ & $0,60(\mathrm{~ns})$ \\
\hline $\begin{array}{l}\text { Espessura de gordura } \\
\text { Fat thicness } \\
\text { Área olho lombo } \\
\text { Loin eye area }\end{array}$ & $0,00(* *)$ & $0,02\left(^{*}\right)$ \\
\hline $\begin{array}{l}\text { Força cisalhamento } \\
\text { Shear force }\end{array}$ & $0,36(\mathrm{~ns})$ & $0,00(* *)$ \\
\hline $\begin{array}{l}\text { Perdas cozimento } \\
\text { Total cooking losses }\end{array}$ & $0,13(\mathrm{~ns})$ & $0,88(\mathrm{~ns})$ \\
\hline
\end{tabular}


variação na disponibilidade de nutrientes, como também em sua qualidade, principalmente no tocante à energia ingerida.

Embora não sejam grupos contemporâneos, a $15^{\mathrm{a}}$ progênie desses rebanhos (nascida em ano anterior à amostra deste estudo), pertencente a uma geração próxima, foi terminada em confinamento, também com animais inteiros (Razook et al., 2001), permitindo uma comparação no desempenho desses atributos, devido principalmente às diferenças ambientais. Naquele estudo, Razook et al. (2001) abateram os animais com peso médio de abate de $476,0 \mathrm{~kg}$, aos 581 dias (19 meses) e condição corporal 8,2, para os mesmos grupos genéticos. O rendimento de carcaça foi maior, oscilando entre 55,6 (GuS) a 58,1\% (NeC). A exemplo deste estudo, os animais dos rebanhos $\mathrm{GuS}$ e $\mathrm{Ca}$ foram os que apresentaram menor rendimento. No estudo de Razook et al. (2001), os animais apresentaram uma quantidade de gordura perirrenal média de $10,4 \mathrm{~kg}$ (2,2\% de $\mathrm{PAB})$, portanto bem superior ao encontrado neste experimento, com médias semelhantes entre os grupos genéticos, e o peso médio do fígado foi praticamente igual à amostra do presente estudo.

$\mathrm{Na}$ composição do corte, os valores de MUSC daquele estudo, um pouco menores em relação a este, oscilaram entre 55,7 (NeC) a 64,7\% (Ca) e, a exemplo deste estudo, superior para $\mathrm{Ca}$ e sem diferenças significativas devido à seleção, comparando-se exclusivamente os animais Nelore. Naquele estudo, o percentual de gordura no corte (GORD) foi maior, com variação de $18,6(\mathrm{Ca})$ a $26,9 \%(\mathrm{NeC})$. Da mesma forma, não houve diferenças significativas entre $\mathrm{NeC}$ e NeS. A porcentagem de osso no corte da amostra estudada por Razook et al. (2001) foi um ponto percentual inferior ao encontrado neste trabalho e, diferentemente deste estudo, que não encontrou diferenças significativas entre os vários grupos, naquele, $\mathrm{NeS}$ apresentou mais OSSO que o Ca.

Nas características consideradas de qualidade de carcaça e carne (Tabela 4) verifica-se que a espessura de gordura no corte do contrafilé variou de 2,0 (Ca) a 4,2 mm (NeC). Embora o teste de Tukey não tenha detectado diferença significativa entre o $\mathrm{NeS}$ e $\mathrm{NeC}$, no contraste específico entre os dois grupos a diferença entre as médias ajustadas $(4,2$ vs 2,9$)$, favorável ao $\mathrm{NeC}$, foi significativa $(\mathrm{P}<0,05)$, embora a sua nota de condição corporal tenha sido menor. Pelos contrastes da Tabela 5 verifica-se que ESPGOR do $\mathrm{NeC}$ foi maior que dos outros grupos e que essa característica de animais $\mathrm{Ca}$ foi menor que de animais Zebu. Esses resultados diferem bastante dos apresentados por Razook et al. (2001). Naquele estudo os autores encontraram valores bem mais altos dessa característica (mínimo de 6,0 em NeC e máximo de 7,5 mm em GuS), sem, contudo, verificar efeitos significativos de rebanhos. Esse grau superior de acabamento, visualisado por uma maior condição corporal no abate da amostra daquele estudo, foi provocado por níveis energéticos adequados na ração de engorda.

Com relação à área de olho de lombo (AOL), os resultados mostram (Tabela 4) que embora tenha havido efeito significativo de rebanhos, o teste Tukey não evidenciou diferenças significativas na comparação múltipla. Por meio dos contrastes, o $\mathrm{NeC}$ apresentou uma AOL inferior aos demais grupos genéticos e o $\mathrm{Ca}$, que apresentou $\mathrm{AOL}$ igual a $\mathrm{NeS}$, não diferiu dos animais Zebu. Esses resultados também contrastam com os de Razook et al. (2001), que encontraram maior AOL para os animais Caracu, em regime de confinamento. A combinação dessas duas características (ESPGOR e AOL) denota certa tendência de grupos selecionados para crescimento, principalmente quando mantidos inteiros, acumularem bastante músculo em regime de pastagem, o que torna a deposição de gordura mais lenta para atingir uma terminação em grau mais desejável. A deposição de gordura em animais inteiros requer uma suplementação energética adequada para que os animais atinjam uma condição corporal superior. Os animais deste estudo só alcançaram a condição corporal acima de 7,0 após uma suplementação com milho, nas águas, por dois meses, antes do abate, já que a condição nutricional encontrada no pasto não foi suficiente para deposição de gordura adequada, permitindo maior desenvolvimento muscular. Essa dificuldade de terminação em pastagem com animais inteiros fica evidente pelo estudo de Euclides et al. (1997), que estudaram várias estratégias de terminação com animais Nelore em pastos de Brachiaria decumbens e, inclusive, adotando confinamento na $2^{\mathrm{a}}$ seca. Esses autores encontraram máxima ESPGOR de 2,4 $\mathrm{mm}\left(\mathrm{AOL}=82,4 \mathrm{~cm}^{2}\right)$, com peso de carcaça de $256 \mathrm{~kg}(\mathrm{REND}=56,8)$, aos 26 meses de idade, em um regime com suplementação alimentar durante o ano todo, com o concentrado composto de $75 \%$ de rolão de milho e $25 \%$ de farelo de soja, na base de $0,8 \%$ do peso vivo médio do lote. 
Tabela 6 - Índice percentual de características de desempenho, abate e carcaça dos rebanhos selecionados em relação ao Nelore controle

Table 6 - Percentual indexes of some performance, slaughter and carcass traits of the selected herds compared to Nellore control

\begin{tabular}{|c|c|c|c|c|}
\hline $\begin{array}{l}\text { Caráter } \\
\text { Trait }\end{array}$ & $\begin{array}{l}\text { Guzerá seleção } \\
\text { Guzerá selection }\end{array}$ & $\begin{array}{l}\text { Nelore controle } \\
\text { Nellore control }\end{array}$ & $\begin{array}{l}\text { Nelore seleção } \\
\text { Nellore selection }\end{array}$ & $\begin{array}{l}\text { Caracu } \\
\text { Caracu }\end{array}$ \\
\hline Peso final PGP aos 378dias & 120,8 & 100,0 & 119,1 & 129,9 \\
\hline $\begin{array}{l}\text { Performance test final weight at } 378 \text { days } \\
\text { Ganho médio diário } \\
\text { Weight daily gain }\end{array}$ & 109,1 & 100,0 & 123,3 & 112,7 \\
\hline $\begin{array}{l}\text { Peso de abate } 824 \text { dias } \\
\text { Slaughter weight at } 824 \text { days }\end{array}$ & 111,9 & 100,0 & 121,2 & 120,0 \\
\hline $\begin{array}{l}\text { Peso de carcaça } \\
\text { carcass weight }\end{array}$ & 107,0 & 100,0 & 124,0 & 119,2 \\
\hline $\begin{array}{l}\text { Rendimento de carcaça } \\
\text { Dressing percentage }\end{array}$ & 95,9 & 100,0 & 100,0 & 98,4 \\
\hline $\begin{array}{l}\text { Peso do fígado } \\
\text { Liver weight }\end{array}$ & 110,4 & 100,0 & 118,7 & 135,4 \\
\hline $\begin{array}{l}\text { Peso da gordura renal } \\
\text { Kidney fat weight }\end{array}$ & 73,3 & 100,0 & 106,7 & 93,3 \\
\hline $\begin{array}{l}\text { Gord. renal }(\%) \\
\text { Kidney fat (\% of SW) }\end{array}$ & 57,1 & 100,0 & 85,7 & 71,4 \\
\hline $\begin{array}{l}\text { Espessura de gordura } \\
\text { Fat thickness }\end{array}$ & 54,8 & 100,0 & 69,0 & 47,6 \\
\hline $\begin{array}{l}\text { Área olho lombo } \\
\text { Loin eye area }\end{array}$ & 101,2 & 100,0 & 109,3 & 109,3 \\
\hline
\end{tabular}

Nas características relacionadas à qualidade da carne, verificou-se que o efeito de rebanhos foi significativo na força de cisalhamento (Tabela 4). A carne de animais $\mathrm{Ca}$ apresentou o menor valor de $\mathrm{FC}$, de $4,5 \mathrm{~kg}$. Esse valor na carne de animais $\mathrm{Ca}$ não diferiu significativamente do $\mathrm{NeS}(5,7)$ pelo teste Tukey. O maior valor foi de $6,6 \mathrm{~kg}$ para GuS, o qual não diferiu significativamente dos animais Nelore. Pelos contrastes (Tabela 5), comprova-se que a FC da carne de animais $\mathrm{NeC}$ não diferiu significativamente dos demais grupos, porém a dos animais Ca é inferior a dos animais Zebu. Com relação às perdas totais (evaporação e gotejamento) de suco da carne, em cozimento em forno, verificou-se que não houve efeito significativo de rebanhos. De acordo com Corte et al. (1979), durante o cozimento, a água e a gordura da carne se fundem, constituindo um suco que, ficando retido na carne, é liberado durante a mastigação, provocando a sensação de suculência. Portanto, quanto menor for a perda desse suco no cozimento, maior é a suculência e, portanto, a carne fica menos seca. Dessa forma, não houve diferenças em relação à qualidade da carne nesse atributo, em relação aos vários grupos genéticos.

Comparando-se com os resultados de Razook et al. (2001) verificou-se que a amostra deste experimento apresentou-se com carne mais dura com base nos valores de FC. Naquele estudo, em animais dos mesmos grupos genéticos, porém terminados em confinamento, e mais jovens, a FC média foi de $4,6 \mathrm{~kg}$, o que representa maciez adequada para o consumo. Neste experimento, com exceção dos animais $\mathrm{Ca}$, todos os grupos apresentaram FC superior a 4,5, o que é considerado como limiar superior para os padrões internacionais de maciez de carne. Vários fatores podem ter levado à maior FC na amostra deste experimento. Conforme esclarece Luchiari Filho, (2000), existem fatores ante e post mortem que interferem na qualidade da carne, mais especificamente sobre a maciez. Como fatores ante mortem, o autor destaca o estresse dos animais devido ao manejo, ao transporte e aos procedimentos de abate, como a utilização de choques elétricos. Nos fatores post mortem, o autor destaca principalmente o $\mathrm{pH}$ da carne que, quando alto, principalmente devido a estresse no abate, produz carne mais dura. Segundo o referido autor, esse problema é mais comum com animais inteiros no momento do abate. Outro fator citado por Luchiari Filho, (2000) é o resfriamento rápido da carcaça, ocasionando o chamado encurta- 
mento celular ("cold shortening") que pode comprometer a maciez, principalmente em animais de carcaça pequena e/ou com pouca cobertura de gordura, conforme ocorreu com a amostra deste estudo. Outra possível explicação para os maiores valores de FC na amostra estudada é a taxa de ganho de peso que foi extremamente variável durante a terminação. De acordo com Felício (1999), a taxa de ganho de peso é uma condição muito importante para determinar a maciez da carne em todos os cortes, devendo superar $800 \mathrm{~g} /$ dia até os 30 meses. Segundo esse autor, o ganho de peso constante é mais importante que o fato de o animal ser jovem.

\section{Conclusões}

Considerando-se os resultados do abate de animais inteiros dos rebanhos Nelore, Guzera e Caracu de Sertãozinho, terminados em pastagem, com idade média de 824 dias e condição corporal 7,6, verificouse que os efeitos indiretos da seleção para peso pósdesmame, em animais Nelore, foram produzir maiores ganhos diários de peso, pesos de abate e de carcaça em relação ao rebanho controle sem, contudo, interferir no rendimento quente de carcaça, e na composição física do corte da costela. Nas características de qualidade de carcaça e de carne, destacase que os animais do rebanho Nelore controle apresentaram melhor cobertura de gordura no momento de abate, porém, não houve efeito da seleção nos indicativos de maciez da carne e de perdas de suco no cozimento. Com referência aos animais dos demais grupos genéticos, destaca-se pesos de abate e carcaça intermediários para o Guzerá, em relação ao Nelore Seleção e Caracu e rendimento de carcaça também inferior aos demais grupos. Os animais Caracu mostraram ter maior proporção de músculo no corte da costela, e sua carne apresentou maior maciez em relação à dos animais Zebu, de acordo com sua menor força de cisalhamento.

\section{Literatura Citada}

BEEF IMPROVEMENT FEDERATION - BIF. Guidelines for uniform beef improvement programs. 7.ed. Reno: University of Nevada, 1996. 153p.

CYRILLO, J.N.S.G.; RAZOOK, A.G.; FIGUEIREDO, L.A. et al. Efeitos da seleção para peso pós-desmame sobre medidas corporais e perímetro escrotal de machos Nelore de Sertãozinho (SP). Revista Brasileira de Zootecnia, v.29, n. 2, p.444-453, 2000 .

CROSS, H.R.; BERNHOLD, H.F.; DIKEMAN, M.E. et al.
Guidelines for cookery and sensory evaluation of meat. Chicago: American Meat Science Association, 1978. 24p.

CORTE, O.O.; FELÍCIO, P.E.; CIA, G. Sistematização da Avaliação Final de Bovinos e Bubalinos - III. Qualidade da Carne. In: Boletim Técnico do Centro de Tecnologia da Carne $n^{\mathbf{0}} 3$.Instituto de Tecnologia de Alimentos. Campinas S.P., 1979. p.67-87.

EUCLIDES FILHO, K.; EUCLIDES, V.P.B; FIGUEIREDO, G.R. et al. Efeito da suplementação com concentrado sobre idade de abate e características de carcaça de bovinos Nelore. Revista Brasileira de Zootecnia, v.26, n.6, p.1096-1102, 1997.

FELÍCIO, P. Austrália prepara sistema com padrão superior para carne bovina. Pecuária de Corte, n.94, p.32-35, 1999.

HANKINS, O.G.; HOWE, P.E. Estimation of the composition of beef carcass and cuts. Washington: United State Departament of Agriculture, 1946. 20p. (Technical Bulletin - USDA).

HARVEY, W.R. User's guide for LSMLMW (Mixed Model Least-Squares and Maxium Likelihood Computer Program). Wooster, Ohio State University, 1990. 91p.

LUCHIARI FILHO, A. Pecuária de corte bovina. 1.ed. São Paulo, 2000. 134p.

NARDON, R.F. Seleção de bovinos para desempenho: composição corporal e características de carcaça. Jaboticabal: Universidade Estadual Paulista, 1998. 107p. Tese (Doutorado em Zootecnia) - Universidade Estadual Paulista, 1998.

NARDON, R.F.; TEDESCHI, L.O.; BOIN, C. et al. Growth performance and carcass composition of Bos indicus and adapted Bos taurus selected based on weight gain after weaning and on adjusted weight at 378 days of age. In: WORLD CONGRESS ON GENETICS APPLIED TO LIVESTOCK PRODUCTION, 6., 1998, Armidale. Proceedings.... Armidale: WCGALP, 1998a. v. 25, p.137-140.

NARDON, R.F.; RAZOOK, A.G.; SAMPAIO, A.A.M. et al. Efeito da seleção para peso pós-desmama e de raças no rendimento em cortes da carcaça e na qualidade da carne de bovinos. In: REUNIÃO ANUAL DA SOCIEDADE BRASILEIRA DE ZOOTECNIA, 35., 1998, Botucatu. Anais... Botucatu: Sociedade Brasileira de Zootecnia, 1998b. p.362-364.

NARDON, R.F.; SAMPAIO, A.A.M.; RAZOOK, A.G. et al. Efeito da seleção para peso pós-desmama e de raças do bovino no rendimento de abate. In: SIMPÓSIO NACIONAL DE MELHORAMENTO ANIMAL, 2., 1998, Uberaba. Anais... Uberaba: Sociedade Brasileira de Melhoramento Animal, 1998c. p.341-342.

PACKER, I.U.; RAZOOK, A.G.; TROVO, J.B.F. et al. Selection for yearling weight in Nelore and Guzerá Zebu breeds: Selection Applied and Response. In: WORLD CONGRESS ON GENETICS APPLIED TO LIVESTOCK PRODUCTION, 3., 1986, Lincoln, Nebraska. Proceedings.... Lincoln: WCGALP, 1986. v.9, p.419-423.

RAZOOK, A.G.; BONILHA NETO, L.M.; FIGUEIREDO, L.A. et al. Seleção para peso pós-desmama em bovinos Nelore e Guzerá. I. Diferenciais e Intensidades de seleção. Boletim de Indústria Animal, v.45, n.2, p.241-271, 1988a.

RAZOOK, A.G.; BONILHA NETO, L.M.; FIGUEIREDO, L.A. et al. Seleção para peso pós-desmama em bovinos Nelore e Guzerá. II. Respostas diretas e correlacionadas. Boletim de Indústria Animal, v.45, n.2, p. 273-315, 1988b.

RAZOOK, A.G.; FIGUEIREDO, L.A.; TROVO, J.B.F. et al. Intensidades de seleção e respostas direta e correlacionadas em 10 anos de progênies de bovinos das raças Nelore e Guzerá selecionadas para peso pós-desmame. Boletim de Indústria Animal, v.50, n.2, p.147-163, 1993. 
RAZOOK, A.G.; FIGUEIREDO, L.A.; CYRILLO, J.N.S.G. et al. Prova de Ganho de Peso. Normas adotadas pela Estação Experimental de Zootecnia de Sertãozinho. Instituto de Zootecnia, Nova Odessa, 1997. 42p. (Boletim Técnico 40)

RAZOOK, A.G.; FIGUEIREDO, L.A.; BONILHA NETO, L.M. et al. Selection for yearling weight in Nelore and Guzerá zebu breeds: selection applied and response in 15 years of progeny. In: WORLD CONGRESS ON GENETICS APPLIED TO LIVESTOCK PRODUCTION, 6., 1998, Armidale. Proceedings.... Armidale: WCGALP, 1998. v.23. p. $133-136$

RAZOOK, A.G.; FIGUEIREDO, L.A.; NARDON, R.F. et al. Efeitos de Raça e da Seleção para Peso Pós-Desmame sobre Características de Confinamento e de Carcaça da $15^{\text {a Progênie }}$ dos Rebanhos Zebu e Caracu de Sertãozinho (SP). Revista Brasileira de Zootecnia, v.30, n.1, p.115-124, 2001.

RESENDE, F.D.; NARDON, R.F.; RAZOOK, A.G. et al. 2000. Desempenho e características de carcaça de zebuínos e Caracu selecionados para peso aos 378 dias de idade, submetidos a dois níveis de energia na terminação. In. REUNIÃO ANUAL DA SOCIEDADE BRASILEIRA DE ZOOTECNIA, 37., 2000, Viçosa. Anais.... Viçosa: SBZ/Gnosis, (2000) CDROM. Nutrição de Ruminantes.NUR-507.

RESENDE, F.D.; OLIVEIRA, J.V.; RAZOOK, A.G. et al. Avaliação das características de carcaça de Zebu e Caracu selecionados para peso aos 378 dias de idade, submetidos a dois níveis de energia na terminação. In: REUNIÃO ANUAL DA SOCIEDADE BRASILEIRA DE ZOOTECNIA, 38., 2001, Piracicaba. Anais.... Piracicaba: Sociedade Brasileira de Zootecnia, 2001, p.532-533.
RUGGIERI, A.C.; FIGUEIREDO, L.A.; CYRILLO, J.N.S.G. et al. Desempenho de novilhos das raças Nelore, Guzerá e Caracu em pastagens tropicais. In: SIMPÓSIO INTERNACIONAL "GRASSLAND ECOPHYSIOLOGY AND ECOLOGY, 1999, Curitiba. Anais.... Curitiba: 1999. p.306-310.

SAS INSTITUTE. Statistical Analysis System. Introductory guide for personal. version 6. Cary: $1985.111 \mathrm{p}$.

VITTORI, A.; QUEIROZ, A.C.; RESENDE, F.D. et al.. Desempenho e características de carcaça de animais Zebu e Caracu - castrados e não-castrados. In: REUNIÃO ANUAL DA SOCIEDADE BRASILEIRA DE ZOOTECNIA, 38., 2001, Piracicaba. Anais... Piracicaba: Sociedade Brasileira de Zootecnia, 2001, p.580-582. 